Quim. Nova, Vol. 34, No. 5, 780-786, 2011

\title{
OTIMIZAÇÃO E VALIDAÇÃO DE MÉTODO EMPREGANDO QUEChERS MODIFICADO E LC-ESI-MS/MS PARA DETERMINAÇÃO DE AGROTÓXICOS EM CEBOLA
}

\author{
Sherol Acosta Rodrigues, Sergiane Souza Caldas, Eliana Badiale Furlong e Ednei Gilberto Primel* \\ Escola de Química e Alimentos, Universidade Federal do Rio Grande, 96201-900 Rio Grande - RS, Brasil \\ Renato Zanella \\ Departamento de Química, Universidade Federal de Santa Maria, 97105-900 Santa Maria - RS, Brasil
}

Recebido em 18/5/10; aceito em 3/12/10; publicado na web em 25/2/11

\begin{abstract}
OPTIMIZATION AND VALIDATION OF A METHOD USING MODIFIED QuEChERS AND LC-ESI-MS/MS FOR THE DETERMINATION OF PESTICIDES IN ONION. An evaluation of the pesticides extraction from onion using a modern sample preparation method (QuEChERS) and determination by liquid chromatography tandem mass spectrometry was carried out. All the calibration curves showed $r>0.99$. The recoveries ranged between 61.8 and $120.0 \%$ with relative standard deviation lower than $20 \%$ for all compounds. Due to the occurrence of matrix effect, the quantification was performed using matrix-matched calibration. The limits of quantification of the method were between 0.0005 and $0.05 \mathrm{mg} \mathrm{kg}^{-1}$. The method shows the advantages of not require the clean-up step and consume low volume of organic solvents, decreasing time, costs and residues.
\end{abstract}

Keywords: pesticides; QuEChERS; LC-ESI-MS/MS.

\section{INTRODUÇÃO}

A cebola (Allium cepa L) está entre os alimentos mais consumidos no mundo. Devido às propriedades antioxidantes e anticancerígenas, é considerada um alimento funcional, por consequência da presença de compostos bioativos, como as antocianinas e a quercetina em sua composição. ${ }^{1-3}$

O maior produtor de cebola do mundo é a China, responsável por cerca de $30 \%$ da produção mundial. Nessa mesma escala, o Brasil está em $9^{\circ}$ lugar, como o maior produtor da América do Sul. ${ }^{4}$

No Brasil, a cebola ocupa a terceira posição em importância econômica, com plantio que se estende desde a região Sul até a região Nordeste. No estado do Rio Grande do Sul, o município do Rio Grande destaca-se com relação à produção. ${ }^{5}$

A cultura da cebola, contudo, é passível de ser atacada por várias doenças de origem fúngica, bacteriana, viral e nematológica, as quais podem ocorrer no campo, na pós-colheita, no transporte, no armazenamento e na comercialização. Como consequência dessa vulnerabilidade, a produtividade da cebola decresce drasticamente, podendo atingir até $100 \%$ de perda na produção de bulbos comercializáveis. ${ }^{6,7}$

Embora o uso de agrotóxicos seja necessário para garantir bons resultados de produtividade, o aumento da aplicação dos mesmos na cultura de cebola ${ }^{8}$ fez com que, em 2008, fosse incluída no Programa de Análise de Resíduos de Agrotóxicos em Alimentos (PARA), iniciado em 2001, pela Agência Nacional de Vigilância Sanitária (ANVISA), com vistas a avaliar continuamente os níveis de resíduos de agrotóxicos presentes nos alimentos in natura que chegam à mesa do consumidor. Das 103 amostras de cebola analisadas, 2,91\% (3 amostras) foram consideradas insatisfatórias, em decorrência, exclusivamente, do uso de acefato, agrotóxico não autorizado para a cultura em estudo. ${ }^{9}$

Entre as dificuldades que envolvem as análises de agrotóxicos

*e-mail: eprimelfurg@gmail.com em amostras de alimentos como a cebola, destaca-se a complexidade dos procedimentos necessários para extração e purificação dessas amostras. A otimização das etapas envolvidas no preparo da mesma é essencial para reduzir o tempo e as fontes de erro relacionadas ao procedimento. ${ }^{10}$

Dentre as técnicas mais utilizadas para a extração de agrotóxicos em alimentos, podem ser citadas a extração acelerada por solvente, ${ }^{11}$ extração líquido-líquido, ${ }^{12}$ extração por ultrassom, ${ }^{13}$ extração com fluido supercrítico ${ }^{14,15}$ e a extração por dispersão da matriz em fase sólida. ${ }^{16-23}$

Nos últimos anos, técnicas e métodos de preparo de amostra baseados na minimização do uso de solventes orgânicos para a extração de agrotóxicos foram desenvolvidos como, por exemplo, o método QuEChERS (Quick, Easy, Cheap, Effective, Ruged and Safe), o qual tem sido largamente empregado para determinação de agrotóxicos em matrizes complexas. Foi assim denominado pelas características que possui: rapidez, facilidade, economia, efetividade, robustez e segurança. É baseado em uma extração com acetonitrila, seguida de partição líquido-líquido (adição de $\mathrm{MgSO}_{4}$ e $\mathrm{NaCl}$ ) e posterior etapa de purificação com extração em fase sólida dispersiva. ${ }^{24-26}$ É um método robusto, ${ }^{27}$ adotado nos EUA, como o oficial da Association of Official Analytical Chemists para a determinação de resíduos de pesticidas em alimentos. ${ }^{28}$ É também considerado método oficial pelo European Committee for Standardization. ${ }^{26,29,30}$

Ao longo de seu desenvolvimento, o método QuEChERS tem sofrido variadas modificações, na direção de ser empregado como um método multirresíduo para extração de agrotóxicos em alimentos, usando técnicas cromatográficas acopladas à espectrometria de massas. ${ }^{20,31,32}$ Nesse contexto, o objetivo do presente estudo foi propor modificações no método QuEChERS, utilizado, no caso, para a extração de resíduos de agrotóxicos em cebola, empregando determinação por cromatografia líquida com fonte de ionização por eletronebulização acoplada à espectrometria de massas sequencial (liquid chromatogtaphy tandem mass spectrometry with electrospray ionization, LC-ESI-MS/MS). 


\section{PARTE EXPERIMENTAL}

\section{Escolha dos agrotóxicos}

Os agrotóxicos foram selecionados a partir de entrevistas com produtores de cebola dos municípios de São José do Norte e Rio Grande, no estado do Rio Grande do Sul. Foram feitas perguntas a respeito dos agrotóxicos mais empregados na cultura de cebola, época de aplicação e a existência de orientação para aplicação dos mesmos.

A partir dos dados obtidos, foi realizada uma pesquisa nas páginas eletrônicas da ANVISA e do Ministério da Agricultura, Pecuária e Abastecimento (MAPA) ${ }^{33,34}$ a fim de identificar quais das substâncias mais empregadas são permitidas para a cultura de cebola e quais poderiam ser determinadas no laboratório. Os agrotóxicos selecionados para o trabalho foram dimetoato, metalaxil-M, tebuconazol, azoxistrobina e difenoconazol. A Figura 1S, material suplementar, apresenta as estruturas químicas dos agrotóxicos estudados. A classe, o grupo químico, os limites máximos de resíduos (LMR) e o intervalo de segurança para agrotóxicos aplicados no cultivo da cebola, na região de Rio Grande, assim como as propriedades físico-químicas de cada substância são apresentados nas Tabelas $1 \mathrm{~S}$ e $2 \mathrm{~S}$, material suplementar. O agrotóxico dimetoato, apesar de não ter LMR estabelecido para a cultura de cebola pela ANVISA, foi escolhido por ter o uso constantemente relatado nas entrevistas com os agricultores e, também, por sua elevada toxicidade.

\section{Instrumentação}

Foi utilizado um cromatógrafo a líquido Alliance Separations modelo 2695 Waters (Milford, MA, USA) equipado com amostrador automático, bomba quaternária, sistema de desgaseificação e coluna analítica Waters XTerra ${ }^{\circledR}$ MS C18 $144 \AA(50 \times 3$ mm, 3,5 $\mu \mathrm{m}$ - Milford, MA, USA), acoplado ao espectrômetro de massas Micromass ${ }^{\circledR}$ Quatro Micro $^{\text {TM }}$ API Waters, com fonte API, utilizando o modo de ionização por eletronebulização e sistema de aquisição de dados via software Masslynx 4.0 Waters.

Para o preparo das amostras de cebola, foi empregado um processador de alimentos, modelo Mega Master Plus RI 3170; Vórtex modelo Certomat ${ }^{\circledR}$ MV-B Braun (Bioteck Internacional, Alemmar Comercial e Industrial S.A.) e centrífuga de tubos microprocessada modelo Quimis ${ }^{\circledR}$ Q222T (Quimis Aparelhos Científicos).

\section{Reagentes}

Os padrões analíticos dos agrotóxicos dimetoato (pureza $\geq$ 99,4\%), metalaxil-M (pureza $\geq 99,0 \%$ ), tebuconazol (pureza $\geq$ $99,6 \%$ ), azoxistrobina (pureza $\geq 97 \%$ ), difenoconazol (pureza $\geq$ 99\%) foram obtidos da Sigma-Aldrich (São Paulo, Brasil). O ácido fórmico grau analítico (pureza 98\%) foi adquirido da Merck (Darmstadt, Alemanha).

Acetonitrila, grau cromatográfico, foi fornecida pela J.T. Baker (Mallinckrodt, Phillisburg, NJ, USA) e a água foi purificada em sistema Direct-Q UV3 ${ }^{\circledR}$ (resistividade 18,2 $\mathrm{M} \Omega \mathrm{cm}$, Millipore, USA). Sulfato de magnésio anidro e cloreto de sódio foram adquiridos da J.T. Baker; bondesil-PSA (40 $\mu \mathrm{m})$ foi obtido da Varian (Palo Alto, CA, USA).

\section{Preparo das soluções analíticas}

As soluções analíticas estoque, contendo $1000 \mathrm{mg} \mathrm{L}^{-1}$ de cada agrotóxico foram preparadas pela dissolução do padrão sólido em metanol, considerando-se o grau de pureza. As soluções foram armazenadas em frasco âmbar e estocadas a $-18^{\circ} \mathrm{C}$.
A partir das soluções estoque de $1000 \mathrm{mg} \mathrm{L}^{-1}$ foram preparadas soluções estoque de concentrações de $100 \mathrm{mg} \mathrm{L}^{-1}$ de cada agrotóxico em metanol. A solução trabalho contendo a mistura dos analitos foi preparada na concentração de $10 \mathrm{mg} \mathrm{L}^{-1}$; foram realizadas diluições para a otimização dos parâmetros de fragmentação, preparo das curvas analíticas e nos ensaios da exatidão. A solução trabalho foi preparada mensalmente, enquanto as diluições utilizadas, diariamente.

\section{Avaliação da vazão da fase móvel}

A fase móvel empregada foi composta por água ultrapura e acetonitrila, acidificadas com $0,1 \%$ de ácido fórmico, na proporção $(52: 48, v / v)$. As vazões da fase móvel testadas foram de 0,2;0,3 e 0,4 $\mathrm{mL} \mathrm{min}^{-1}$. Os solventes empregados na fase móvel foram filtrados a vácuo, através de membranas de nylon 0,45 $\mu \mathrm{m}$, e desgaseificados em banho de ultrassom durante $30 \mathrm{~min}$, à temperatura ambiente.

\section{Otimização dos parâmetros de fragmentação}

A otimização dos parâmetros de fragmentação foi realizada com vistas a selecionar as melhores condições de fragmentação dos íons na análise por MS. Para tanto, foram realizadas infusões diretas no espectrômetro de massas com solução analítica na concentração de $1,0 \mathrm{mg} \mathrm{L}{ }^{-1}$ de cada agrotóxico estudado. Os parâmetros variados foram: voltagem do cone, energia de colisão, temperatura da fonte, temperatura e vazão do gás de dessolvatação, voltagem do capilar e do cone extrator. A etapa de otimização das condições de fragmentação foi determinante para selecionar os íons a serem monitorados para qualificação e quantificação dos agrotóxicos estudados.

\section{Otimização do procedimento de extração}

Em 2008, um método empregando QuEChERS modificado para determinação de agrotóxicos em frutas e vegetais foi desenvolvido. ${ }^{32}$ Neste trabalho, foram realizadas modificações no método proposto, sendo realizados testes para avaliar a influência da etapa de purificação e da adição de cloreto de sódio na exatidão do método.

\section{Avaliação da influência da etapa de purificação na exatidão do método}

O procedimento foi realizado com a pesagem de $10,0 \mathrm{~g}$ de amostra processada em um tubo de polipropileno (capacidade 50,0 mL), seguida por etapa de fortificação no nível de $1,0 \mathrm{mg} \mathrm{kg}^{-1}$, realizada através da adição de volume conhecido de solução padrão $(100,0 \mu \mathrm{L})$ à amostra sólida. Em seguida, $10,0 \mathrm{~mL}$ de acetonitrila foram adicionados, seguido por agitação manual (15 s) e agitação em vórtex (1 min). Após, foram adicionados 4,0 $\mathrm{g}$ de sulfato de magnésio anidro e repetida a etapa de agitação; finalmente, o tubo foi centrifugado a $5000 \mathrm{rpm}$ durante $3 \mathrm{~min}$. Para o procedimento sem a etapa de purificação, uma alíquota do extrato foi retirada e $10,0 \mu \mathrm{L}$ injetados no sistema cromatográfico.

Para o procedimento com etapa de purificação, $6,0 \mathrm{~mL}$ do extrato foram transferidos para um tubo de polipropileno (capacidade 15,0 $\mathrm{mL}$ ), contendo $150,0 \mathrm{mg}$ de amina primária-secundária (primary secondary amine, PSA) e 950,0 mg de $\mathrm{MgSO}_{4}$, seguido pelas etapas de agitação e centrifugação. Uma alíquota do extrato final foi retirada e 10,0 $\mu \mathrm{L}$ foram injetados no sistema cromatográfico.

\section{Avaliação da influência de $\mathrm{NaCl}$ na extração}

Métodos empregados em trabalhos prévios utilizam sais como $\mathrm{MgSO}_{4}$ e NaCl . Assim, foram realizados testes comparando-se os resultados de recuperação, ao se empregar os dois sais ou apenas $\mathrm{MgSO}_{4} \cdot{ }^{24,32} \mathrm{~A}$ adição de sais promove o efeito salting out, incremen- 
tando o nível de recuperação para analitos mais polares e diminui a solubilidade dessas substâncias na fase aquosa, bem como a quantidade de água na fase orgânica. ${ }^{26}$

Para a realização dos testes foram pesados 10,0 g de amostra em 6 tubos de polipropileno (capacidade $50,0 \mathrm{~mL}$ ). Por sua vez, as amostras foram fortificadas no nível de $1,0 \mathrm{mg} \mathrm{kg}^{-1} \mathrm{e}$ foram adicionados 10,0 $\mathrm{mL}$ de acetonitrila em cada tubo; em 3 tubos foram adicionados 4,0 g de $\mathrm{MgSO}_{4}$ e $1,0 \mathrm{~g}$ de $\mathrm{NaCl}$ e, nas três amostras restantes, foram adicionados apenas $4,0 \mathrm{~g} \mathrm{MgSO}_{4} \mathrm{O}$ restante do procedimento foi realizado sem a etapa de purificação.

\section{Avaliação do efeito de matriz.(EM)}

Para avaliar o EM, foram injetadas no sistema cromatográfico uma solução padrão com a mistura dos agrotóxicos, na concentração de $1,0 \mathrm{mg} \mathrm{L}^{-1}$, diluída no extrato branco da matriz (extraído pelo método proposto) e uma outra solução padrão com a mistura dos agrotóxicos diluída com metanol. O cálculo do EM (\%) foi baseado na bibliografia. ${ }^{35}$

\section{Validação do método}

O método foi validado, avaliando-se os seguintes itens: curva analítica, linearidade, limite de detecção (limit of detection, LOD), limite de quantificação (limit of quantification, LOQ), exatidão (recuperação) e precisão (repetibilidade e precisão intermediária), parâmetros sugeridos pelo Instituto Nacional de Metrologia, Normalização e Qualidade Industrial (INMETRO) e pela ANVISA. ${ }^{36,37}$

\section{Curva analítica e linearidade}

A linearidade do instrumento e do método foi avaliada pelas curvas analíticas através de padronização externa no solvente e por superposição da matriz com soluções analíticas nas concentrações de 0,$0005 ; 0,005 ; 0,05 ; 0,5$ e $1,0 \mathrm{mg} \mathrm{L}^{-1}$.

Para padronização externa por superposição da matriz, foram preparadas soluções analíticas através de diluições da solução padrão de trabalho com o extrato da matriz. Os procedimentos foram realizados com a matriz isenta de agrotóxicos e a padronização externa no solvente foi estabelecida por diluições da solução padrão de trabalho com metanol.

Cada solução foi injetada três vezes e os dados de regressão linear foram obtidos com auxílio do software do equipamento.

\section{Limites de detecção e quantificação}

Os limites de detecção $\left(\mathrm{LOD}_{\mathrm{m}}\right)$ e quantificação $\left(\mathrm{LOQ}_{\mathrm{m}}\right)$ do método foram obtidos pela injeção de soluções analíticas de diferentes concentrações, preparadas através de diluições da solução padrão de trabalho no extrato da matriz. O $\mathrm{LOD}_{\mathrm{m}}$ e o $\mathrm{LOQ}_{\mathrm{m}}$ para cada agrotóxico foram estimados a partir da relação sinal/ruído, calculada pelo software do equipamento, considerando, no mínimo, 3 e 10 vezes a razão do sinal pela linha de base (ruído), respectivamente.

\section{Exatidão}

A exatidão do método foi avaliada em função dos ensaios de recuperação, de acordo com as determinações da ANVISA e do International Conference Harmonisation. ${ }^{38}$ Amostras de cebola (isentas de agrotóxicos) foram fortificadas nos níveis de 0,0005 ; 0,005; 0,05 e $1,0 \mathrm{mg} \mathrm{kg}^{-1}$, a partir da adição de um volume conhecido de solução padrão de trabalho com a mistura dos agrotóxicos a $10,0 \mathrm{~g}$ de amostra.

\section{Precisão}

A precisão instrumental foi avaliada a partir de injeções sucessivas de solução analítica padrão, com a mistura dos agrotóxicos $(n=7)$, e estimada através do coeficiente de variação $(\mathrm{CV})$ com relação à média das áreas de todas as injeções.

A precisão do método foi avaliada em função da repetibilidade e da precisão intermediária. Para o estudo da repetibilidade, foi realizada a extração da amostra fortificada com solução analítica padrão e com a mistura dos agrotóxicos em diferentes níveis de fortificação, em triplicata; cada nível foi injetado três vezes. A partir das 9 determinações, foi calculado o $\mathrm{CV}(\%) .{ }^{38} \mathrm{~A}$ precisão intermediária foi avaliada, assim como a repetibilidade, porém em diferentes dias e com diferentes analistas.

\section{RESULTADOS E DISCUSSÃO}

\section{Avaliação da vazão da fase móvel}

A melhor composição de fase móvel foi a mistura de acetonitrila e água ultrapura, acidificadas com $0,1 \%$ de ácido fórmico, na proporção de $\left(52: 48\right.$, v/v) e vazão de $0,4 \mathrm{~mL} \mathrm{~min}^{-1}$. Um cromatograma para a separação é apresentado na Figura 1. A acidificação permite que haja prótons suficientes na solução para que principalmente a espécie protonada esteja na solução, dissolvida na fase móvel, consequência (do controle) da distribuição de espécies. O pH menor proporciona maior interação entre as substâncias e a fase estacionária, mais apolar, aumenta a retenção da substância. Além disso, a acidificação da fase móvel também auxilia na ionização dos analitos. ${ }^{39,40}$

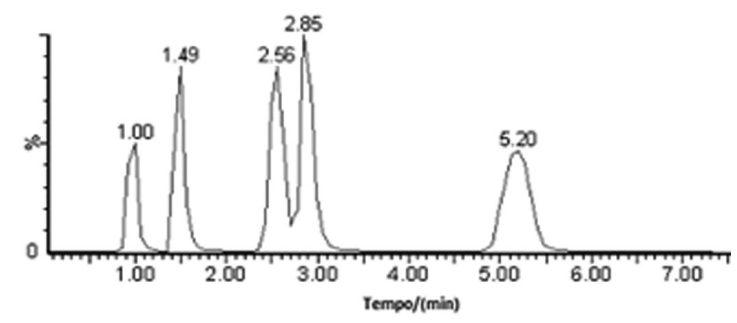

Figura 1. Cromatogramas de ions totais dos agrotóxicos estudados em solução (1,0 $\left.\mathrm{mg} \mathrm{L}^{-1}\right)$. Dimetoato (1,00 min), metalaxil-M (1,49 min), azoxistrobina (2,56 min), tebuconazol (2,85 min) e difenoconazol (5,20 min)

Ao se empregar a espectrometria de massas em série, através do modo de aquisição de monitoramento de reações múltiplas (MRM), é possível quantificar compostos que coeluem através do monitoramento das transições íon precursor - íon produto de cada substância. Assim, LC-MS/MS assegura a identificação com maior exatidão do que quando ela é feita apenas com base nas características de retenção das substâncias analisadas, como ocorre nas outras técnicas de detecção cromatográficas. ${ }^{41}$ Entretanto, a separação cromatográfica é importante para assegurar a eficiência da ionização dos analitos, diminuindo possíveis efeitos de matriz. ${ }^{35}$

\section{Parâmetros de fragmentação otimizados}

Foi utilizada a interface ESI, a mais indicada para substâncias neutras ou polares, que podem ser protononadas ou deprotonadas em condições apropriadas de $\mathrm{pH} .{ }^{42}$

As melhores condições para a fragmentação dos íons monitorados, obtidas com infusões diretas no espectrômetro de massas na vazão de $10,0 \mu \mathrm{L} \min ^{-1}$, foram: temperatura de $100{ }^{\circ} \mathrm{C}$ na fonte; temperatura do gás $\mathrm{N}_{2}$ (gás de dessolvatação) de $350{ }^{\circ} \mathrm{C}$, mantida a uma vazão para a dessolvatação da amostra de $350 \mathrm{~L} \mathrm{~h}^{-1}$ e para o cone de seleção dos íons $50 \mathrm{~L} \mathrm{~h}^{-1}$; a energia do capilar foi $4 \mathrm{kV}$ e no segundo cone, o extrator foi $3 \mathrm{~V}$.

Na Tabela 1 são apresentadas as transições monitoradas no modo 
Tabela 1. Condições de fragmentação para determinação dos agrotóxicos por LC-ESI-MS/MS

\begin{tabular}{|c|c|c|c|c|c|}
\hline Agrotóxicos & \multicolumn{2}{|c|}{ MRM transição $(\mathrm{m} / \mathrm{z})$} & Energia de colisão $(\mathrm{eV})$ & Voltagem do cone $(\mathrm{V})$ & $t_{R}(\min )$ \\
\hline Dimetoato & $\begin{array}{l}230>125 \\
230>199\end{array}$ & $\begin{array}{l}\text { Quantificação } \\
\text { Qualificação }\end{array}$ & $\begin{array}{l}20 \\
10\end{array}$ & $\begin{array}{l}16 \\
20\end{array}$ & 1,00 \\
\hline Metalaxil-M & $\begin{array}{l}280>220 \\
280>192\end{array}$ & $\begin{array}{l}\text { Quantificação } \\
\text { Qualificação }\end{array}$ & $\begin{array}{l}17 \\
17\end{array}$ & $\begin{array}{l}16 \\
16\end{array}$ & 1,49 \\
\hline Tebuconazol & $\begin{array}{c}308>70 \\
308>125\end{array}$ & $\begin{array}{l}\text { Quantificação } \\
\text { Qualificação }\end{array}$ & $\begin{array}{l}20 \\
22\end{array}$ & $\begin{array}{l}40 \\
28\end{array}$ & 2,85 \\
\hline Azoxistrobina & $\begin{array}{l}404>372 \\
404>329\end{array}$ & $\begin{array}{l}\text { Quantificação } \\
\text { Qualificação }\end{array}$ & $\begin{array}{l}20 \\
30\end{array}$ & $\begin{array}{l}20 \\
15\end{array}$ & 2,56 \\
\hline Difenoconazol & $\begin{array}{l}406>251 \\
406>337\end{array}$ & $\begin{array}{c}\text { Quantificação } \\
\text { Qualificação }\end{array}$ & $\begin{array}{l}31 \\
20\end{array}$ & $\begin{array}{l}31 \\
32\end{array}$ & 5,20 \\
\hline
\end{tabular}

Dwell Time (tempo de janela): 0,3 s

ESI (+), modo de aquisição MRM, energia de colisão, voltagem do cone e tempo de retenção dos agrotóxicos estudados.

Para cada analito foram selecionadas duas transições características, o que é possibilitado por um analisador de massas sequencial (tandem). A transição mais intensa (mais estável) foi escolhida para quantificação, enquanto a segunda, para confirmação.

\section{Procedimento de extração}

\section{Avaliação da influência da etapa de purificação na exatidão do método}

De acordo com os resultados de recuperação (R\%) apresentados na Figura 2, é possível verificar que os valores de recuperação foram similares para a maioria dos agrotóxicos estudados com e sem a etapa de purificação. Para o primeiro caso, recuperações na faixa de 86,7 e $108,9 \%$ foram obtidas e, no segundo, as recuperações ficaram na faixa de 85,4 e 107,1\%. Considerando que as possíveis interferências da matriz são compensadas pelo emprego de padronização externa por superposição da mesma, neste trabalho foi estabelecido o desenvolvimento do processo sem a etapa de purificação, a fim de tornar o procedimento de preparo da amostra ainda mais rápido e diminuir o consumo de reagentes.

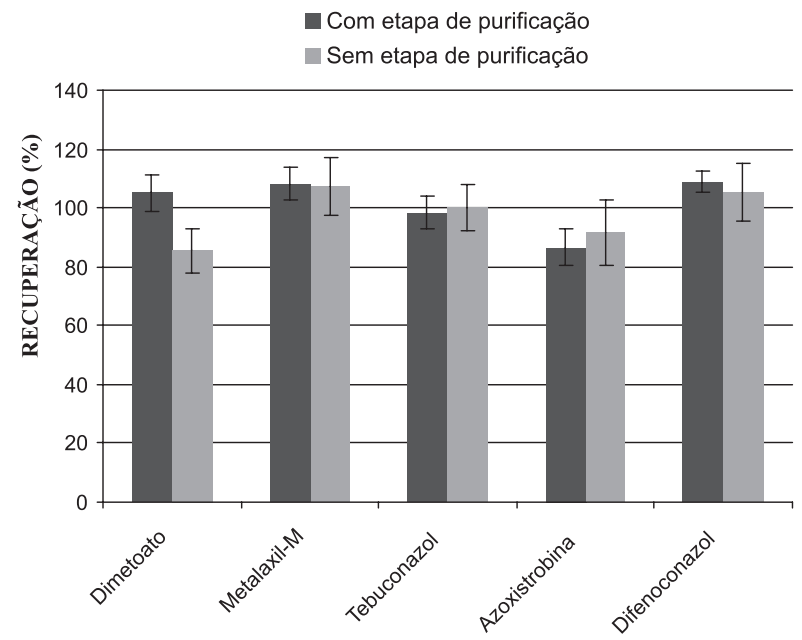

Figura 2. Comparação entre o método QuEChERS modificado, no nível de $1,0 \mathrm{mg} \mathrm{kg}^{-1}$, com e sem emprego da etapa de purificação. As barras de erro significam $C V(\%)(n=9)$

\section{Influência de $\mathrm{NaCl}$ na extração}

Na Figura 3 são apresentados os resultados de recuperação, os quais indicam que a adição de cloreto de sódio em combinação ao sulfato de magnésio, conforme empregado em trabalhos prévios, gera valores de recuperação maiores para a maioria das substâncias quando comparados aos da adição de apenas $\mathrm{MgSO}_{4} \cdot{ }^{24,32}$

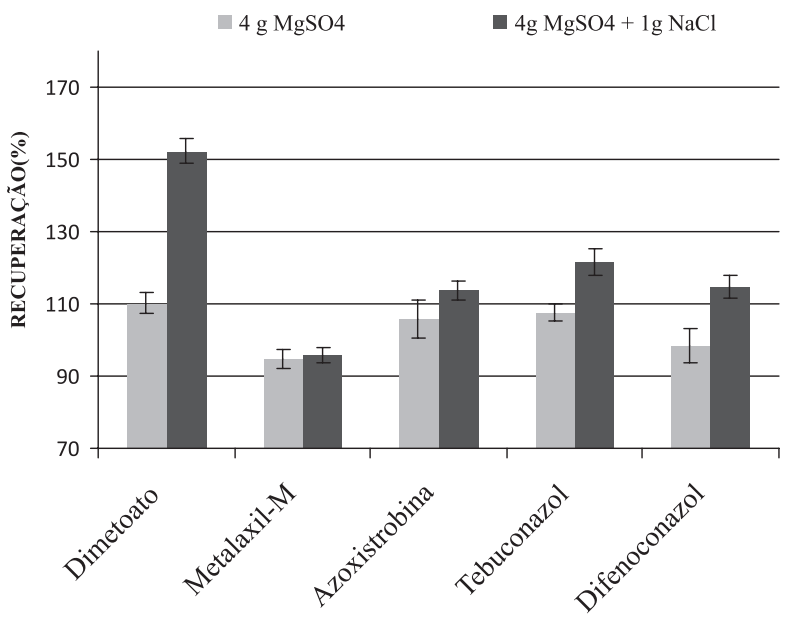

Figura 3. Valores de recuperação (\%) para os agrotóxicos em relação aos sais adicionados no processo de extração. As barras de erro significam $C V(\%)(n=9)$

Entretanto, para dimetoato, o valor de recuperação está acima de $150 \%$, o que não é aceitável para a determinação de compostos traços em matrizes complexas e, além disso, $\mathrm{MgSO}_{4}$ quando empregado sozinho, é suficiente para gerar resultados de recuperação entre 70 e $120 \%$ para todos os analitos.

O valor elevado de recuperação para dimetoato pode ser explicado pelo fato de que o sal, além de favorecer a extração dos analitos, também aumenta a coextração de componentes da matriz, o que pode ter favorecido o enriquecimento do sinal. Assim, somente $\mathrm{MgSO}_{4}$ foi adicionado aos extratos, por possuir alta capacidade de remover água, quando comparado a outros sais. ${ }^{24}$

Efeito matriz

No método proposto foi constatado efeito matriz para o agrotóxico dimetoato. Essa influência se deve provavelmente à quantidade de interferentes presentes na amostra, ocasionando interferência na ionização dos analitos. Devido às interferências dos componentes da matriz no processo de ionização, a quantificação dos agrotóxicos foi realizada através de superposição da matriz. Na Figura 4, além do EM\%, são apresentados resultados das recuperações dos agrotóxicos em diferentes formas de quantificação. Quando a recuperação é avaliada por comparação com as curvas no solvente, os valores variam de 49,0 a 105,0\% 
com CV de 0,6 a 3,6\% e, quando avaliada por meio da comparação por superposição na matriz, os valores para recuperação variaram de 89,6 a $114,1 \%$ com CV de 0,2 a 1,4\%. O EM\% variou de 28,0 a $100,0 \%$ com $\mathrm{CV}$ de 0,8 a 2,3\%, comprovando, assim, a necessidade de quantificação dos agrotóxicos através de superposição da matriz.

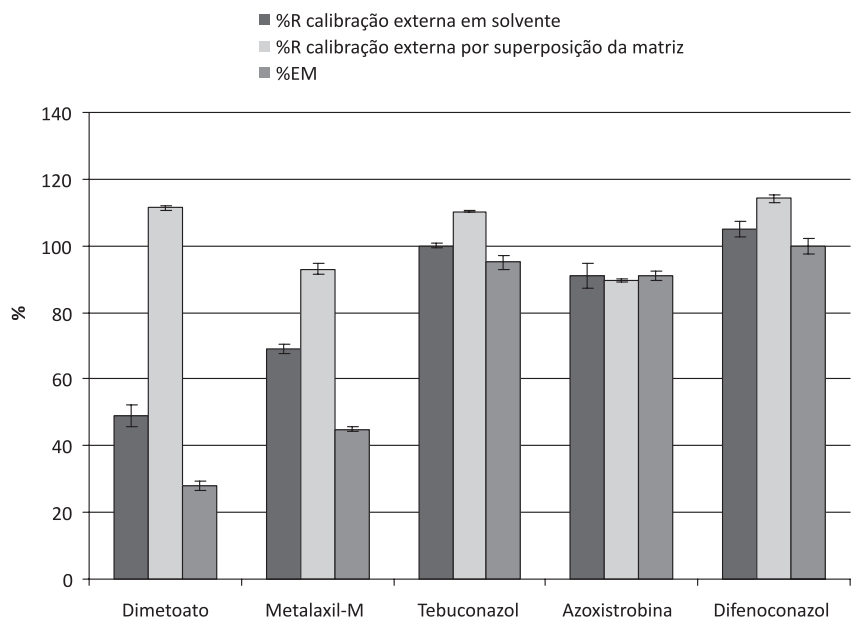

Figura 4. Comparação entre as recuperações dos agrotóxicos por QuEChERS, nível de fortificação $1,0 \mathrm{mg} \mathrm{kg}^{-1}$, empregando diferentes formas de quantificação e efeito matriz para todos os agrotóxicos. As barras de erro significam $C V(\%)(n=9)$

\section{Procedimento de extração otimizado}

Na Tabela 2 são apresentadas as condições otimizadas para o método QuEChERS modificado, proposto no presente trabalho com relação a outros métodos, empregando QuEChERS, propostas em trabalhos anteriores. ${ }^{24,32}$ De acordo com os dados apresentados, é possível observar a diferença entre os métodos e afirmar que o proposto neste trabalho utiliza menor quantidade de reagentes e apresenta maior rapidez no procedimento de extração.

\section{Validação do método}

\section{Curva analítica e linearidade}

Através dos dados obtidos para a construção das curvas analíticas e análise das equações das retas no LC-ESI-MS/MS, é possível concluir que o modelo de regressão linear é adequado para as determinações analíticas em estudo. De acordo com a Tabela 3, os coeficientes de correlação ( $r$ ) foram maiores que 0,99 , estando de acordo com as orientações da ANVISA e do INMETRO, que recomendam, respectivamente, $r \geq 0,99$ e $r \geq 0,90 .{ }^{36,37}$

\section{Limites de detecção e de quantificação}

Os $\mathrm{LOD}_{\mathrm{m}}$ e $\mathrm{LOQ}_{\mathrm{m}}$ dos métodos foram de 0,016 e $0,05 \mathrm{mg} \mathrm{kg}^{-1}$ para o dimetoato; de 0,0016 e $0,005 \mathrm{mg} \mathrm{kg}^{-1}$ para o metalaxil-M e de 0,00016 e $0,0005 \mathrm{mg} \mathrm{kg}^{-1}$ para difenoconazol, azoxistrobina e tebuconazol.
Tabela 2. Comparação entre o método QuEChERS original, o método de Lesueur e o método proposto

\begin{tabular}{lccc}
\hline QuEChERS & Original $^{24}$ & Modificado $^{32}$ & Este estudo \\
\hline Amostra & $10,0 \mathrm{~g}$ & $10,0 \mathrm{~g}$ & $10,0 \mathrm{~g}$ \\
Acetonitrila & $10,0 \mathrm{~mL}$ & $10,0 \mathrm{~mL}$ & $10,0 \mathrm{~mL}$ \\
Agitação & $60 \mathrm{~s}$ & $60 \mathrm{~s}$ & $60 \mathrm{~s}$ \\
$\mathrm{MgSO}_{4}$ & $4,0 \mathrm{~g}$ & $4,0 \mathrm{~g}$ & $4,0 \mathrm{~g}$ \\
$\mathrm{NaCl}$ & $1,0 \mathrm{~g}$ & $1,0 \mathrm{~g}$ & - \\
Citrato de sódio & - & $1,0 \mathrm{~g}$ & - \\
Hidrogenocitrato de sódio & - & $0,5 \mathrm{~g}$ & - \\
Agitação & $60 \mathrm{~s}$ & $60 \mathrm{~s}$ & $60 \mathrm{~s}$ \\
Padrão interno & tirfenilfosfato & Trifenilfosfato & - \\
Agitação & $30 \mathrm{~s}$ & - & - \\
Centrifugação & $5 \mathrm{~min}$ & $3 \mathrm{~min}$ & $3 \mathrm{~min}$ \\
Alíquota do extrato & $5000 \mathrm{rpm}$ & $5000 \mathrm{rpm}$ & $5000 \mathrm{rpm}$ \\
PSA & $1,0 \mathrm{~mL}$ & $6,0 \mathrm{~mL}$ & - \\
MgSO & $25,0 \mathrm{mg}$ & $150,0 \mathrm{mg}$ & - \\
Centrifugação & $150,0 \mathrm{mg}$ & $950,0 \mathrm{mg}$ & - \\
& $1 \mathrm{~min}$ & $3 \mathrm{~min}$ & - \\
Determinação & $6000 \mathrm{rpm}$ & $5000 \mathrm{rpm}$ & - \\
\hline
\end{tabular}

Os limites de quantificação do método alcançaram valores menores que os limites máximos de resíduos estabelecidos pela ANVISA, para metalaxil-M, tebuconazol, azoxistrobina e difenoconazol. No que se refere ao agrotóxico dimetoato, não há LMR estabelecido para a cultura de cebola, por não ser indicado para aplicação na mesma.

\section{Exatidão}

Os processos mais utilizados para avaliar a exatidão de um método analítico são: materiais de referência, comparação de métodos, ensaios de recuperação e adição de padrão. Neste trabalho a exatidão foi avaliada por ensaios de recuperação. ${ }^{38}$ Para os ensaios de recuperação, diferentes níveis de concentração do analito foram empregados, visto que a eficiência do método pode variar em função da quantidade da substância adicionada.

A literatura sobre validação de métodos cromatográficos indica que os intervalos de recuperação aceitáveis para a determinação de resíduos devem estar entre 70 e $120 \%$, com precisão de até $\pm 20 \% .38,40,43$ Os valores de recuperação e de $\mathrm{CV}(\%)$ são apresentados na Tabela 4. Os valores de recuperação variaram de 65,2 a $120,0 \%$, com CV variando entre 3,3 e 20,0\% para a repetibilidade e de 61,8 a 116,7\%, com CV variando entre 2,0 e 20,0\% para precisão intermediária em todos os níveis de fortificação.

\section{Precisão}

A precisão instrumental foi avaliada a partir de injeções sucessivas de solução analítica padrão na concentração de $0,05 \mathrm{mg} \mathrm{L}^{-1}(\mathrm{n}=7)$. Os valores de $\mathrm{CV}(\%)$ das áreas de todas as

Tabela 3. Resultados para as curvas analíticas e linearidade

\begin{tabular}{lccc}
\hline Agrotóxicos & Curva analítica no solvente & r & Curva analítica na matriz \\
\hline Dimetoato & $\mathrm{y}=29306,7 \mathrm{x}+12,247$ & 0,998 & $\mathrm{y}=7951,9 \mathrm{x}+3,59037$ \\
Metalaxil-M & $\mathrm{y}=106839 \mathrm{x}+49,0445$ & 0,993 & $\mathrm{y}=43794,5 \mathrm{x}-9,50831$ \\
Tebuconazol & $\mathrm{y}=174947 \mathrm{x}+68,5335$ & 0,999 & $\mathrm{y}=159082 \mathrm{x}+409,68$ \\
Azoxistrobina & $\mathrm{y}=218045 \mathrm{x}+223,502$ & 0,991 & $\mathrm{y}=124042 \mathrm{x}+19,2466 \quad 0,998$ \\
Difenoconazol & $\mathrm{y}=130623 \mathrm{x}+17,9105$ & 0,999 & $\mathrm{y}=124487 \mathrm{x}+183,681$ \\
\hline
\end{tabular}


Tabela 4. Recuperação, $\mathrm{CV}_{\mathrm{r}}$ e $\mathrm{CV}_{\mathrm{pi}}$ para os agrotóxicos em amostras de cebola fortificadas em diferentes níveis

\begin{tabular}{|c|c|c|c|c|c|}
\hline Agrotóxico & $\begin{array}{l}\text { Nível de fortificação } \\
\left(\mathrm{mg} \mathrm{kg}^{-1}\right)\end{array}$ & $\begin{array}{c}\text { Recuperação } \\
(\%)\end{array}$ & $\begin{array}{l}\mathrm{CV}_{\mathrm{r}} \\
(\%)\end{array}$ & $\begin{array}{c}\text { Recuperação } \\
(\%)\end{array}$ & $\begin{array}{l}\mathrm{CV}_{\mathrm{pi}} \\
(\%)\end{array}$ \\
\hline Dimetoato & $\begin{array}{c}0,0005 \\
0,005 \\
0,05 \\
1,0\end{array}$ & $\begin{array}{c}- \\
- \\
92,3 \\
85,3\end{array}$ & $\begin{array}{c}- \\
- \\
6,9 \\
7,3\end{array}$ & $\begin{array}{c}- \\
- \\
116,7 \\
111,3\end{array}$ & $\begin{array}{c} \\
- \\
7,7 \\
4,2\end{array}$ \\
\hline Metalaxil-M & $\begin{array}{c}0,0005 \\
0,005 \\
0,05 \\
1,0\end{array}$ & $\begin{array}{c}- \\
97,6 \\
81,4 \\
107,1\end{array}$ & $\begin{array}{c}- \\
19,4 \\
6,4 \\
9,7\end{array}$ & $\begin{array}{c}- \\
93,8 \\
96,3 \\
93,0\end{array}$ & $\begin{array}{c}- \\
16,4 \\
7,3 \\
4,0\end{array}$ \\
\hline Tebuconazol & $\begin{array}{c}0,0005 \\
0,005 \\
0,05 \\
1,0\end{array}$ & $\begin{array}{c}107,0 \\
86,1 \\
98,7 \\
100,1\end{array}$ & $\begin{array}{l}7,2 \\
9,0 \\
3,6 \\
7,9\end{array}$ & $\begin{array}{c}96,8 \\
61,8 \\
103,8 \\
110,3\end{array}$ & $\begin{array}{c}8,5 \\
14,3 \\
2,7 \\
2,0\end{array}$ \\
\hline Azoxistrobina & $\begin{array}{c}0,0005 \\
0,005 \\
0,05 \\
1,0\end{array}$ & $\begin{array}{c}65,2 \\
109,8 \\
87,4 \\
91,8\end{array}$ & $\begin{array}{c}20,0 \\
10,4 \\
9,0 \\
11,0\end{array}$ & $\begin{array}{l}86,7 \\
83,3 \\
90,7 \\
89,6\end{array}$ & $\begin{array}{c}20,0 \\
6,3 \\
3,8 \\
3,7\end{array}$ \\
\hline Difenoconazol & $\begin{array}{c}0,0005 \\
0,005 \\
0,05 \\
1,0\end{array}$ & $\begin{array}{l}115,2 \\
120,0 \\
104,1 \\
105,3\end{array}$ & $\begin{array}{c}12,7 \\
11,1 \\
3,3 \\
9,8\end{array}$ & $\begin{array}{c}108,2 \\
75,4 \\
108,5 \\
114,1\end{array}$ & $\begin{array}{c}17,6 \\
11,4 \\
4,1 \\
3,7\end{array}$ \\
\hline
\end{tabular}

injeções foram: $10,5 \%$ para dimetoato; $6,7 \%$ para matelaxil-M; $7,8 \%$ para tebuconazol; $6,4 \%$ para azoxistrobina e $5,3 \%$ para difenoconazol.

A precisão do método foi avaliada em função da repetibilidade e da precisão intermediária, estimadas de acordo com as recomendações da ANVISA. ${ }^{37}$ Os valores de CV(\%) para os estudos de repetibilidade $\left(\mathrm{CV}_{\mathrm{r}}\right)$ e precisão intermediária $\left(\mathrm{CV}_{\mathrm{pi}}\right)$ ficaram na faixa de 3,3-20,0\% e 2,0-20,0\%, respectivamente. Os valores mais detalhados de $\mathrm{CV}_{\mathrm{r}}$ e $\mathrm{CV}_{\mathrm{pi}}$ são apresentados, juntamente com os resultados de recuperação, na Tabela 4.

Para o dimetoato, os valores de $\mathrm{CV}_{\mathrm{r}}$ e $\mathrm{CV}_{\mathrm{pi}}$ foram estimados a partir de dois níveis de concentração. Isso porque o referido agrotóxico apresentou menor sensibilidade no sistema LC-ESIMS/MS, relacionado às outras substâncias. A precisão do método foi avaliada em quatro níveis de fortificação. Os valores de CV para a repetibilidade e precisão intermediária, além de menores que $20 \%$, ficaram muito próximos, indicando a adequada precisão do método. ${ }^{38}$

\section{Aplicação do método}

O método empregando QuEChERS modificado e LC-ESI-MS/ MS, após ser validado, foi aplicado para determinação de resíduos dos agrotóxicos dimetoato, metalaxil-M, tebuconazol, azoxistrobina e difenoconazol. As amostras de cebola foram coletadas em um supermercado e em uma propriedade rural na região e resíduos de agrotóxicos não foram encontrados.

\section{CONCLUSÕES}

Os resultados obtidos neste estudo permitem concluir que o método empregando QuEChERS modificado e LC-ESI-MS/MS para a determinação dos agrotóxicos dimetoato, metalaxil-M, tebuconazol, azoxistrobina e difenoconazol em cebola é eficiente, rápido, preciso e exato.

O método QuEChERS modificado foi robusto e altamente reprodutível, uma vez que elevadas recuperações foram alcançadas. Além disso, o procedimento de extração é extremamente rápido e não necessita emprego da etapa de purificação dos extratos de cebola.
Entretanto, os componentes da matriz afetaram a eficiência da ionização de alguns analitos por LC-ESI-MS/MS e a influência do efeito matriz para dimetoato, metalaxil-M e azoxitrobina definiu o modo de quantificação dos analitos por calibração externa, através da superposição da matriz.

As condições cromatográficas e os parâmetros de fragmentação otimizados para determinação por LC-ESI-MS/MS permitiram a identificação e a quantificação dos agrotóxicos em estudo, em um tempo de análise menor que 6 min.

As curvas analíticas apresentaram valores de $r$ maiores que 0,99 para as faixas de concentração necessárias às aplicações. Os valores médios de recuperação obtidos em diferentes níveis de fortificação estiveram na faixa de 61,8 a $120,0 \%$, com valores de $\mathrm{CV}(\%)$ menores que $20 \%$. Os limites de quantificação do método variaram na faixa de 0,0005 a $0,05 \mathrm{mg} \mathrm{kg}^{-1}$.

O limite de quantificação do método para todos os analitos foi menor que os limites máximos de resíduos definidos pela legislação brasileira, ANVISA, para tais agrotóxicos em cebola. O fato é de suma importância, uma vez que o Brasil, em 2008, assumiu a liderança mundial no consumo de agrotóxicos, segundo dados do SINDAG; em função disso, no mesmo ano, o PARA incluiu a cebola em seu programa de monitoramento.

\section{MATERIAL SUPLEMENTAR}

Está disponível em http://quimicanova.sbq.org.br, na forma de arquivo PDF, com acesso livre. A Tabela $1 \mathrm{~S}$ apresenta a classe, o grupo químico, os LMR e o intervalo de segurança para agrotóxicos aplicados no cultivo da cebola, na região de Rio Grande. A Tabela $2 \mathrm{~S}$ apresenta constante de acidez $\left(\mathrm{pK}_{\mathrm{a}}\right)$, coeficiente de partição octanol/água $\left(\mathrm{K}_{\mathrm{ow}}\right)$, solubilidade em água e pressão de vapor de cada substância para agrotóxicos em estudo e a Figura $1 \mathrm{~S}$, as estruturas químicas dos agrotóxicos estudados.

\section{REFERÊNCIAS}

1. Roldán, E.; Sánchez-Moreno, C.; Ancos, B.; Cano, M. P.; Food Chem. 2008, 108, 907.

2. Dini, I.; Tenore, G. C; Dini, A.; Food Chem. 2008, 107, 613.

3. Praksh, D.; Singh, B. N; Upadhyay, G.; Food Chem. 2007, 102, 1389. 
4. http://sistemasdeproducao.cnptia.embrapa.br/FontesHTML/Cebola/ CultivoCebolaNordeste/socioeconomia.htm, acessada em Outubro 2009.

5. http://www.ibge.gov.br/cidadesat/topwindow.htm?1, acessada em Outubro 2009.

6. http://www.cnph.embrapa.br/sistprod/cebola/caracteristicas_nutricionais. htm, acessada em Outubro 2009.

7. Soares, D. J.; Pitelli, R. A.; Braz, L. T.; Gravena, R.; Toledo, R. E. B.; Planta Daninha 2003, 21, 387.

8. Boff, P.; Debarba, J. F.; Silva, E.; Werner, H.; Horticultura Brasileira 2005, 23, 875 .

9. http://www.anvisa.gov.br/divulga/noticias/2009/pdf/150409_para.pdf, acessada em Outubro 2009.

10. Prestes, O. D.; Dissertação de Mestrado, Universidade Federal de Santa Maria, Brasil, 2007.

11. Chuang, J. C.; Hart, K.; Chang, J. S.; Boman, L. E.; Emon, J. M. V.; Reed, A. W.; Anal. Chim. Acta 2001, 444, 87.

12. Tahboub, Y. R.; Zaater, M. F.; Barri, T. A.; Anal. Chim. Acta 2006, 558, 62.

13. Rezic', I.; Horvat, A. J. M.; Babic', S.; Kastelan-Macan, M.; Ultrason. Sonochem. 2005, 12, 477.

14. Lehotay, S. J.; J. Chromatogr., A 1997, 785, 289.

15. Rissato, S. R.; Galhiane, M. S.; Knoll, F. R. N.; Apon, B. M.; J. Chromatogr., A 2004, 148, 143.

16. García-López, M.; Canosa, P.; Rodríguez, I.; Anal. Bioanal. Chem. 2008, 391, 963.

17. Rodrigues, S. A.; Caldas, S. S.; Primel, E. G.; Anal. Chim. Acta 2010, $678,82$.

18. Blasco, C.; Picó, Y.; Mañes, J.; Font, G.; J. Chromatogr., A 2002, 947, 227.

19. Dórea, H. D.; Lopes, W. G.; Quim. Nova 2004, 27, 892.

20. Wang, S.; Xu, Y.; Pan, C.; Jiang, S.; Liu, F.; Anal. Bioanal. Chem. 2007, 387,673 .

21. Wu, R.; Dang, Y.; Niu, L.; Hua, H.; J. Food Compos. Anal. 2008, 21, 582.

22. Yang, Y.; Shao, B.; Zhang, J.; Wu, Y.; Ying, J.; J. Chromatogr., B: Anal. Technol. Biomed. Life Sci. 2008, 870, 241.

23. Pinho, G. P.; Neves, A. A.; Queiroz, M. E. L. R.; Quim. Nova 2009, 32, 92.

24. Anastassiades, M.; Lehotay, S. J.; Stajnbaher, D.; Schenck, F. J.; J. AOAC Int. 2003, 86, 412.
25. Romero-Gonzáles, R.; Frenich, A. G.; Vidal, J. L. M.; Talanta 2008, 76, 211.

26. Prestes, O. D.; Friggi, C. A.; Adaime, M. B.; Zanella, R.; Quim. Nova 2009, 32, 1620 .

27. Lehotay, S. J.; J. AOAC Int. 2007, 90, 485.

28. AOAC; Official Method 2007.01: Pesticide residues in foods by acetonitrile extraction and partitioning with magnesium sulphate, AOAC International, 2007.

29. http://www.codexalimentarius.net, acessada em Outubro 2009.

30. http://europa.eu/index_pt.htm, acessada em Outubro 2009.

31. Lehotay, S. J.; Kok, A.; Hiemstra, M.; Bodegraven, P. V.; J. AOAC Int. 2005, $88,595$.

32. Lesueur, C.; Knittl, P.; Gartner, M.; Mentler, A.; Fuerhacker, M.; Food Control 2008, 785, 289.

33. http://www.anvisa.gov.br, acessada em Outubro 2009.

34. http://agrofit.agricultura.gov.br/agrofit_cons/principal_agrofit_con, acessada em Outubro 2009.

35. Kruve, A.; Künnapas, A.; Herodes, K.; Leito, I.; Anal. Chim. Acta 2008, $1187,58$.

36. Instituto Nacional de Metrologia, Normalização e Qualidade Industrial (INMETRO); Orientações sobre Validação de Métodos de Ensaios Químicos, DOQ-CGCRE-008. Revisão: 01, 2003.

37. Agência Nacional de Vigilância Sanitária (ANVISA); Guia para Validação de Métodos Analíticos e Bioanalíticos, RE nº 889, de 29 de maio de 2003.

38. Ribani, M.; Bottoli, C. B. G.; Collins, C. H.; Jardim, I. C. S. F.; Melo, L. F. C.; Quim. Nova 2004, 27, 771.

39. Kuster, M.; Alda, M. L.; Barceló, D.; Mass Spectrom. Rev. 2006, 25 , 900.

40. Caldas, S. S.; Demoliner, A.; Costa, F. P.; D’Oca, M. G. M.; Primel, E. G.; J. Braz. Chem. Soc. 2010, 21, 642.

41. Chiaradia, M. C.; Collins, C. H.; Jardim, I. C. S. F.; Quim. Nova 2008 , 31,623 .

42. Ardrey, R. E.; Liquid Chromatography - Mass Spectrometry: An Introduction; John Wiley \& Sons Ltd, 2003, p. 276.

43. Brito, N. M.; Junior, O. P. A.; Polese, L.; Santos, T. C. R.; Ribeiro, M. L.; R. Ecotoxicol. e Meio Ambiente 2003, 13, 129. 

PARA DETERMINAÇÃO DE AGROTÓXICOS EM CEBOLA

Sherol Acosta Rodrigues, Sergiane Souza Caldas, Eliana Badiale Furlong e Ednei Gilberto Primel*

Escola de Química e Alimentos, Universidade Federal do Rio Grande, 96201-900 Rio Grande - RS, Brasil

Renato Zanella

Departamento de Química, Universidade Federal de Santa Maria, 97105-900 Santa Maria - RS, Brasil

Tabela 1S. Classe, grupo químico, limites máximos de resíduos (LMR) e intervalo de segurança para agrotóxicos aplicados no cultivo da cebola, na região de Rio Grande

\begin{tabular}{|c|c|c|c|c|c|}
\hline Agrotóxico & Classe & Grupo químico & $\begin{array}{c}\text { LMR } \\
\left(\mathrm{mg} \mathrm{kg}^{-1}\right) \text { CODEX } \\
\end{array}$ & $\begin{array}{c}\text { LMR } \\
\left(\mathrm{mg} \mathrm{kg}^{-1}\right) \text { ANVISA } \\
\end{array}$ & $\begin{array}{l}\text { Intervalo de segurança } \\
\text { (dias) }\end{array}$ \\
\hline azoxistrobina & fungicida & estrobilurina & - & 0,05 & 2 \\
\hline bentazona & herbicida & benzotiadiazinona & - & - & - \\
\hline captana & fungicida & diocarboximida & - & 10,0 & 7 \\
\hline deltametrina & inseticida/formicida & piretroide & - & 0,03 & 2 \\
\hline dimetoato & inseticida & organofosforado & - & - & - \\
\hline difenoconazol & fungicida & triazol & - & 0,1 & 7 \\
\hline glifosato & herbicida & glicina substituída & - & - & - \\
\hline iprodiona & fungicida & dicarboximida & 0,2 & 1,0 & 14 \\
\hline linurom & herbicida & ureia & - & 0,2 & 60 \\
\hline mancozebe & fungicida/acaricida & ditiocarbamato & - & 0,2 & 7 \\
\hline metalaxil-M & fungicida & fenilamida & - & 0,5 & 7 \\
\hline pendimetalina & herbicida & dinitroanilina & - & 0,1 & 1 \\
\hline propinebe & fungicida & ditiocarbamato & 0,5 & 1,0 & 7 \\
\hline tebuconazol & fungicida & triazol & - & 0,1 & 14 \\
\hline trifluralina & herbicida & dinitroanilina & - & 0,05 & 1 \\
\hline $2,4-\mathrm{D}$ & herbicida & ácido fenoxiacético & - & - & - \\
\hline
\end{tabular}

*e-mail: eprimelfurg@gmail.com 
Tabela 2S. Propriedades físico-químicas dos agrotóxicos selecionados para estudo ${ }^{1,2}$

\begin{tabular}{lcccc}
\hline Agrotóxico & $\mathrm{pk}_{\mathrm{a}}$ & $\log \mathrm{K}_{\mathrm{ow}}$ & Solubilidade em água $\left(\mathrm{g} \mathrm{L}^{-1}\right)$ & Pressão de vapor $(\mathrm{mPa})$ \\
\hline dimetoato & 2,0 & 0,7 & 23,3 & $0,25\left(25^{\circ} \mathrm{C}\right)$ \\
metalaxil-m & 1,4 & 1,7 & 26,0 & $3,3\left(25^{\circ} \mathrm{C}\right)$ \\
tebuconazol & - & 3,7 & 0,036 & $1,710^{-3}\left(20^{\circ} \mathrm{C}\right)$ \\
azoxistrobina & $-0,67$ & 2,5 & 0,06 & $1,110^{-7}\left(20^{\circ} \mathrm{C}\right)$ \\
difenoconazol & 3,0 & 1,1 & 0,015 & $3,310^{-5}\left(25^{\circ} \mathrm{C}\right)$ \\
\hline
\end{tabular}

1. Tomlin, C. D. S.; The e-Pesticide Manual, 13 ed. Versão 3.0. Londres. 2003-2004. 2. Montes, R.; Rodríguez, I.; Ramil, M.; Rubí, E.; Cela, L.; J. Chromatogr., A 2009, 1216, 5459.

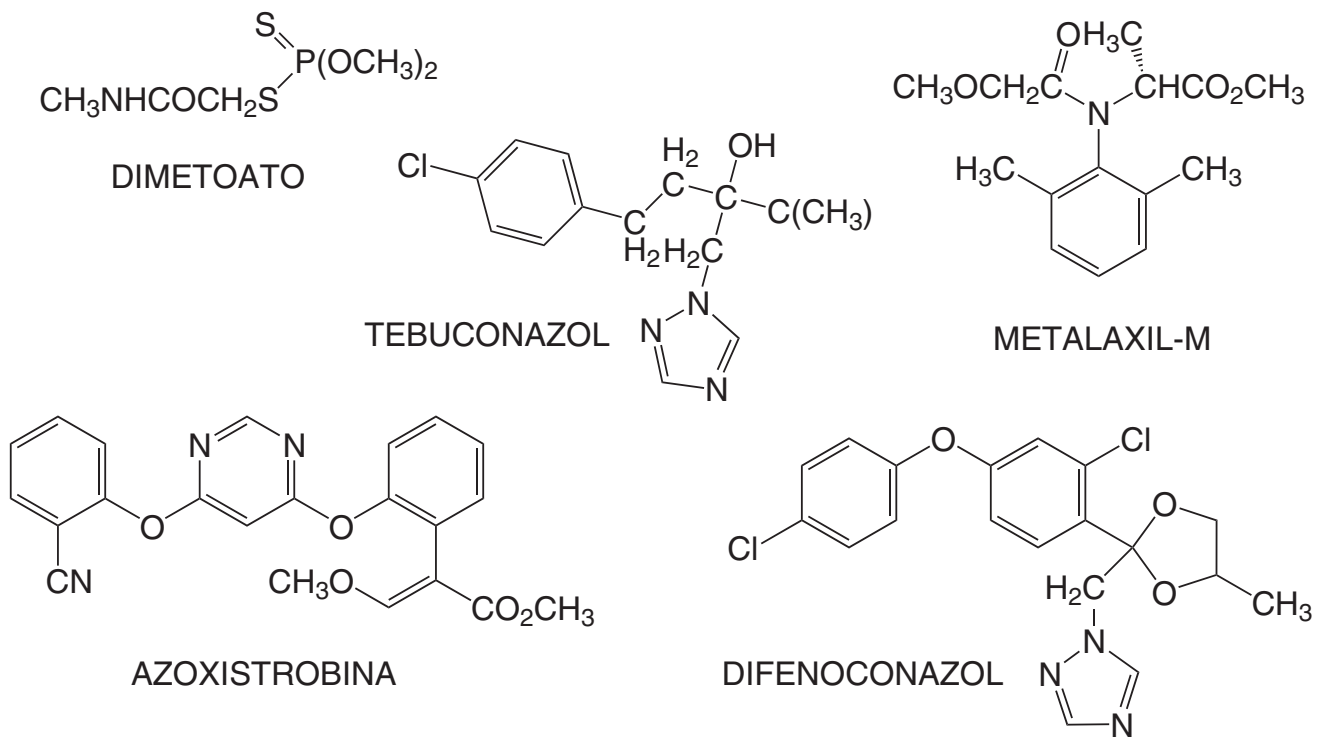

Figura 1S. Estruturas químicas dos agrotóxicos estudados 